\title{
LA DEGRADACIÓN DE DUNAS LITORALES EN ANDALUCÍA: APROXIMACIÓN GEOHISTÓRICA Y MULTIESCALAR
}

\author{
José Gómez Zotano \\ Instituto de Desarrollo Regional. Departamento de Análisis Geográfico Regional y Geografía Física \\ Universidad de Granada
}

\section{RESUMEN}

Desde mediados del siglo pasado, las costas de la comunidad autónoma de Andalucía han conocido un acelerado proceso de urbanización que, como factor social de primer orden, ha provocado -y provoca en la actualidad- una degradación ambiental y paisajística generalizada, especialmente acusada en los ecosistemas dunares. Los sistemas playa-duna, frágiles y cambiantes por naturaleza, pese a constituir un patrimonio natural estratégico, de alto valor eco-cultural y socioeconómico, han sufrido un fuerte retroceso que no ha sido cuantificado ni georreferenciado. Con objeto de conocer la magnitud de dichos cambios, se presenta un análisis multiescalar y geohistórico fundamentado en la fotointerpretación y la cartografía: en primer lugar se identifican, a escala regional, los espacios dunares que han sufrido una regresión superficial, y se evidencia que Andalucía ha dilapidado 1/3 de los arenales costeros en seis décadas. En segundo lugar se analiza, a escala local, un caso de dunas amenazadas, paradigmático y extensible al resto del territorio.

Palabras clave: sistema playa-duna, litoral, urbanización, evolución del paisaje, Andalucía.

\section{ABSTRACT}

\section{Coastal dune degradation in Andalusia: a spatiotemporal and multiscale approach}

Since the middle of the last century the coasts of Andalusia have undergone a process of rapid urbanization as a major social factor, which has caused -and is now causing- environmental and landscape degradation that has been especially prevalent in dune ecosystems. Coastal dunes, fragile by nature, in spite of representing a strategic natural heritage, as well as having high eco-cultural and socioeconomic value, have suffered serious damage that has not been quantified or georeferenced up to the present time. In order to ascertain the magnitude of these changes, this study presents a geohistorical and multiscale analysis, based on photo interpretation and mapping: first identified, at regional level, sand dunes that have been lost surface area, and evidence that Andalusia has lost 1/3 of foredune systems over the last six decades. Secondly, analyzed a local case of a threatened dune, which is paradigmatic and may be extended to the rest of the Spanish coastline.

Key words: Foredunes system, coast, construction activities, landscape evolution, Andalusia.

\section{INTRODUCCIÓN}

Los espacios litorales del sur de Europa han experimentado en los últimos 60 años un continuado proceso de ocupación intensiva derivado, fundamentalmente, de dos tipos de actividades económicas, aparentemente antagónicas: el turismo y la agricultura. En relación directa con la primera destaca la urbanización del suelo, la más categórica e irreversible de las transformaciones producidas por el ser humano. Ésta ha conocido un proceso de litoralización sin precedentes que, de acuerdo con Brown y McLachlan (1990), Rust y Illenberg (1996), McKinney (2006) y Sanjaume y Pardo-Pascual (2011), ha dado lugar a la interrupción de los mecanismos naturales de formación y defensa de los frágiles y dinámicos sistemas litorales, y a la mutación imprevista de los paisajes costeros.

Contacto: jgzotano@ugr.es 
Especialmente problemática ha sido la urbanización de los sistemas playa-duna; aquí tienen lugar complejas relaciones e intercambios de los que resulta un delicado equilibrio natural, muy vulnerable a las alteraciones externas, a las que cabe sumar el uso y regeneración de playas turísticas, la construcción de puertos o la invasión de especies exóticas. Desde Portugal a Turquía, la transformación generalizada de las dunas litorales se explica por su secular consideración como espacios marginales e improductivos, siendo puntual, y relativamente reciente, la gestión integrada de las mismas (Van der Meulen y Salman, 1996; Brown y McLachlan, 2002; Martínez et al, 2008). En cualquier caso, el retroceso experimentado por los sistemas playa-duna de Europa meridional no ha sido aún cuantificado ni georreferenciado.

España no se encuentra al margen de este problema. A escala regional, la comunidad autónoma de Andalucía constituye un buen ejemplo del proceso urbanizador de dunas litorales que no ha sido analizado conjuntamente desde la perspectiva espacio-temporal. Además, es un territorio particularmente geo y biodiverso, donde se han implementado ambiciosas iniciativas para la normalización y difusión de la información, así como para la gobernanza de los espacios costeros. En primer lugar, el litoral andaluz alberga sobresalientes sistemas playa-duna, tanto por su extensión superficial, como por su valor ambiental y paisajístico. Si bien estos arenales suelen ser asociados con fijeza al litoral atlántico, cabe recordar que en la costa mediterránea también se desarrollan importantes campos de dunas litorales.

En segundo lugar, Andalucía ha realizado amplios esfuerzos por generar información detallada del ámbito litoral con la puesta en marcha del Subsistema de Información del Litoral y Medio Marino o del Sistema Compartido de Información de Paisaje de Andalucía (http://www.juntadeandalucia.es/ medioambiente/site/rediam/).

En tercer lugar, la comunidad autónoma cuenta con una vasta serie de instrumentos de planificación que afectan al litoral: los Planes Especiales de Protección del Medio Físico, las Directrices Regionales del Litoral y el Informe al respecto del Defensor del Pueblo Andaluz; el Plan de Ordenación del Territorio de Andalucía (POTA), los Planes Subregionales costeros y el planeamiento general municipal; la Estrategia Andaluza de Gestión Integrada de Zonas Costeras, meramente indicativa, y el Plan de Protección del Corredor Litoral de Andalucía, en trámite; y la Red de Espacios Naturales Protegidos de Andalucía (RENPA; Parque Nacional de Doñana, Parque Natural del Cabo de Gata-Níjar, Parajes Naturales de Enebrales de Punta Umbría y Punta Entinas-Sabinar, Parques Periurbanos de las Dunas de San Antón y La Barrosa, Monumentos Naturales de los Acantilados del Asperillo, Duna de Bolonia y Dunas de Artola o Cabopino).

A pesar de los importantes logros conseguidos, el ejercicio continuado de la actividad urbanizadora en los últimos 60 años, y la ausencia de un deslinde del dominio público marítimo-terrestre actualizado, completo y fiable (Torres Alfosea, 2009; Garrido y López, 2010), ha desatado un proceso de ocupación de la costa andaluza, unas veces estacional y otras -las más- permanente, que ha supuesto la introducción de nuevos factores interactuantes con los sistemas playa-duna. Estos factores, en la mayoría de los casos, han operado negativamente sobre el equilibrio general de los arenales, produciendo o induciendo degradaciones irreversibles e indeseables en aquellos municipios más turísticos (EEA, 2006). A la alteración de los procesos naturales, se suma la regulación de cuencas hidrográficas y la obstrucción de los sedimentos circulantes, consecuencia de la construcción de numerosas infraestructuras hidráulicas (206 presas y embalses) y portuarias (52 puertos) (Junta de Andalucía 2008, 2013).

Actualmente, desde la desembocadura del río Guadiana (frontera con Portugal) a la Cala Cerrada (límite con Murcia), los gestores del territorio andaluz, sabedores de que en una economía basada en el sector terciario la pérdida de litoral supone la merma de capacidad turística, aprueban, en determinados tramos, la urbanización de valiosos ecosistemas dunares (Greenpeace, 2010). Sobresalen aquellos casos que han generado una mayor alarma social y demandan una atención urgente, como Valdevaqueros en Tarifa (provincia de Cádiz) o el Saladillo-Matas Verdes en Estepona (provincia de Málaga).

A tenor de la problemática expuesta, los objetivos de la presente investigación consisten en conocer, a escala regional, la superficie de los sistemas playa-dunas andaluces y la magnitud de los cambios que el urbanismo expansivo, como principal factor de degradación ambiental, ha generado en ellos. De igual modo, pretende comprender la dinámica temporal, tanto de la configuración, como de los procesos que afectan al paisaje litoral pasado y actual, centrándose en el estudio de un caso particular a escala local (complejo dunar Saladillo-Matas Verdes). 


\section{METODOLOGÍA}

\subsection{Proceso metodológico}

La metodología utilizada para la consecución de los objetivos planteados se basa en la comparación de imágenes aéreas y mapas temáticos, lo que permite llevar a cabo, con apoyo de los SIG (Arc Gis 10), un análisis geohistórico y georreferenciado de los territorios citados, desde mediados del siglo XX hasta la actualidad. En una primera fase se ha realizado un análisis multitemporal a escala regional (litoral de Andalucía) contrastando la información superficial correspondiente a la categoría "Playas, dunas y arenales" contenida en los "Mapas de usos y coberturas vegetales de los años 1956 y 2007" a escala 1:25.000 de la Consejería de Medio Ambiente de la Junta de Andalucía. Considerando la dificultad para obtener resultados cartográficos visibles del conjunto del litoral andaluz, y las limitaciones de la fuente de partida (no desagrega la información relativa a las dunas y presenta errores de fotointerpretación de los arenales litorales de las provincias de Granada y Almería especialmente), se ha optado por representar estadísticamente los cambios operados entre los dos cortes temporales contemplados. Las transformaciones generadas por la dinámica litoral en el perfil costero de Andalucía, considerables en las provincias de Huelva o Almería entre las fechas contempladas, impiden el contraste de la información de partida con el "Mapa de unidades fisiográficas del litoral de Andalucía" (Junta de Andalucía, 2010), más reciente, y contenedor de información detallada sobre tres categorías de interés: formaciones dunares, formaciones sedimentarias litorales (flechas, tómbolos, etc.) y mantos eólicos.

En una segunda fase se ha procedido al análisis multianual más detallado (litoral del Saladillo-Matas Verdes). A escala local (1:10.000), la secuencia temporal considerada comprende los siguientes años y fuentes: 1956 (vuelo americano), 1977 (Ministerio de Agricultura), 1994 y 2007 (Junta de Andalucía). Las imágenes han sido fotointerpretadas con criterios ecológicos/fisiográficos para discriminar los arenales costeros. También se ha levantado la información relativa al suelo urbanizado en cada uno de los cortes temporales. Con la información obtenida se han elaborado cuatro mapas representados a escala 1:25.000 que permiten la visualización del comportamiento espacial de los sistemas playa-duna. Además, en 2007 se ha realizado un vuelo aéreo para la toma de fotografías oblicuas y actualizadas del litoral que permiten su contrastación con otras efectuadas durante las décadas de los 60 y 70 del siglo XX por la empresa "Paisajes Españoles".

Para la explicación de los resultados cartográficos se han considerado el planeamiento y la legislación urbanística que, en cada periodo temporal analizado, ha afectado al ámbito de estudio a distintas escalas espaciales. La recopilación y revisión bibliográfica ha completado ambas fases del método.

\section{2. Ámbito de estudio}

A escala regional, el ámbito de estudio está constituido por el litoral de Andalucía (figura la). Con $1.101 \mathrm{~km}$ de longitud, se reparte entre el Océano Atlántico y el Mar Mediterráneo, acogiendo una extraordinaria variedad de sistemas costeros y marinos: dunas litorales, playas, praderas de fanerógamas marinas, estuarios, deltas, acantilados, etc. Todos estos espacios naturales son de vital importancia para la supervivencia de las costas, siendo los sistemas playa-dunas las formaciones naturales que mejor representan el dinamismo y fragilidad de este tipo de medios, tanto a un lado, como al otro del Estrecho de Gibraltar. En ellos se da una fuerte interrelación entre arena, viento y vegetación, ejerciendo una reconocida función de protección y conservación de los frentes costeros. De igual modo, albergan una gran riqueza biológica, al tiempo que representan un atractivo paisajístico para las demandadas zonas costeras andaluzas, constituyendo el principal activo medioambiental sobre el que se basa el sector turístico de la comunidad autónoma.

En la costa atlántica, baja y arenosa, se extienden extensos arenales litorales como Doñana, Bolonia o Valdevaqueros. En la accidentada costa mediterránea, en cambio, los arenales son más modestos, aunque no por ello menos valiosos ambientalmente, pues reflejan una interesante gradación pluviométrica en sentido W-E (Matas Verdes, Artola, Guadalfeo, Punta Entinas-Sabinar, Mónsul) que tiene un fiel reflejo en la explotación biológica de las arenas y la conformación de los ecosistemas subsiguientes.

En cualquier caso, el elevado valor geo-estratégico y la riqueza ecológica y patrimonial de las costas andaluzas ha provocado un progresivo aumento de los conflictos de usos en un territorio frágil, relativamente pequeño e inevitablemente limitado, que se ha saldado con la desaparición y alteración 
de kilómetros de arenales litorales; una política de hechos consumados en la que generalmente no se ha considerado la participación ciudadana.

Figura 1. Ámbitos de estudio; a, Andalucía; b, complejo dunar Saladillo-Matas Verdes

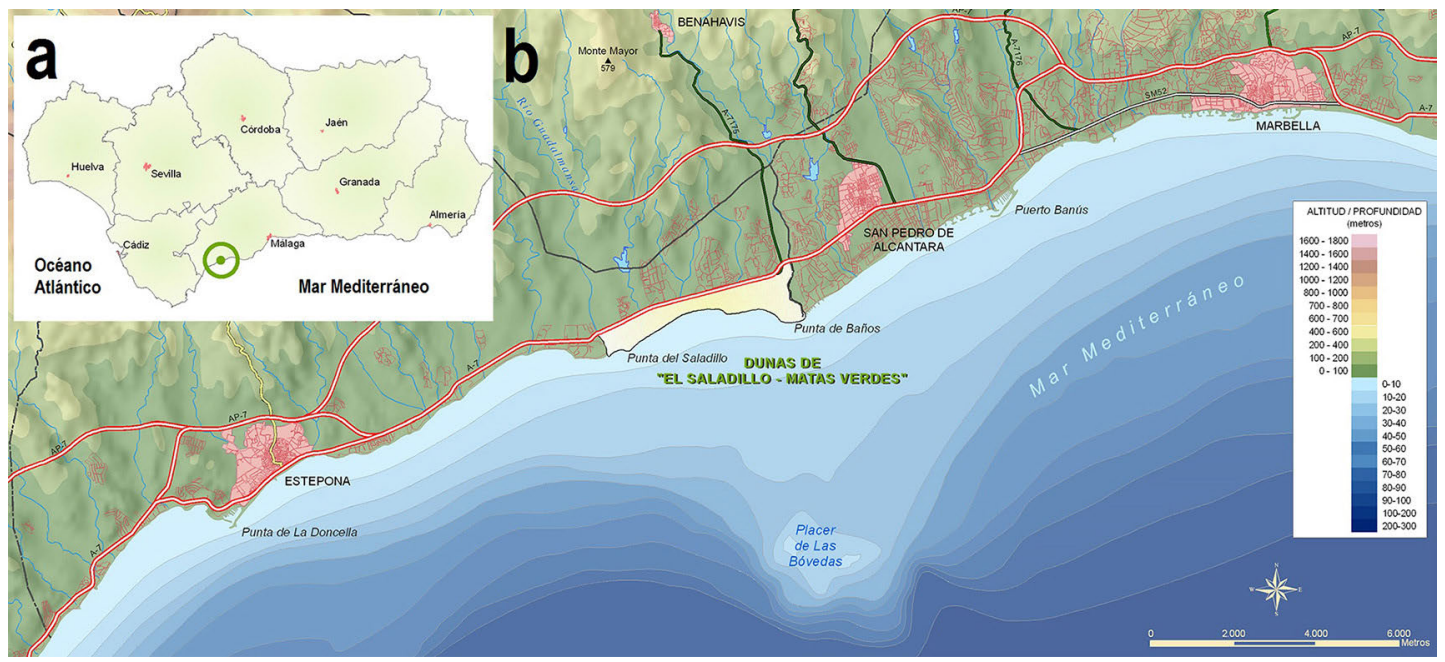

Fuente: Instituto de Cartografía de Andalucía. Elaboración propia

A escala local, el ámbito de estudio contemplado se sitúa en el litoral mediterráneo andaluz. Se trata de un complejo dunar denominado Saladillo-Matas Verdes, perteneciente al municipio malagueño de Estepona. Este arenal, poco conocido, se desarrolla a lo largo de un borde costero de $6 \mathrm{~km}$ de longitud que comprende las playas de Guadalmansa, El Saladillo y Casasola, entre las desembocaduras de los ríos Guadalmansa al Oeste y Guadalmina (Punta de Baños) al Este. Al Norte, el ámbito de estudio queda delimitado por la A-7 (antigua N-340), y al Sur, por el mar Mediterráneo (figura 1b). En las 314,6 has de superficie que tiene el tramo costero en su totalidad, se desarrollan unas dunas que alcanzan una altura máxima de $6 \mathrm{~m}$ y se adentran $200 \mathrm{~m}$ hacia el interior (figura 2).

Figura 2. Dunas del Saladillo-Matas Verdes, un paisaje de dominante natural desconocido en la actualmente urbanizada Costa del Sol

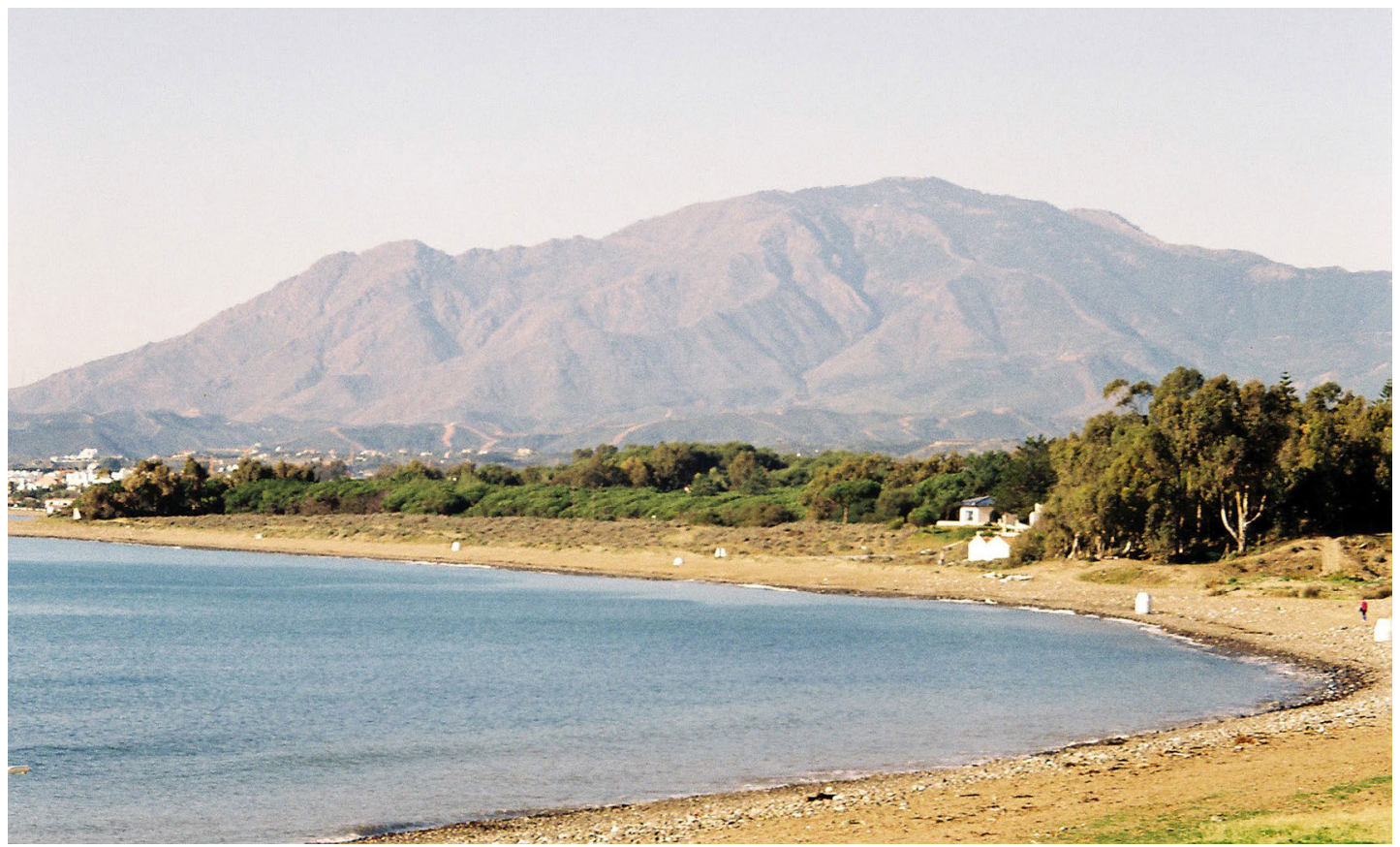

Foto: José Gómez Zotano 
Se trata del único complejo dunar que se conserva en la antropizada costa de Estepona, y uno de los pocos existentes en el litoral mediterráneo andaluz -junto con el de Artola en Marbella-, donde se pueden identificar, con gran detalle, los cinco estadios morfológicos (dunas pioneras, embrionarias, móviles, semifijas y fijas), valles dunares y campo postdunar. Conserva, por tanto, algunas de las escasas dunas estabilizadas y edafizadas que han sobrevivido a la acción conjugada del turismo y la urbanización, con la serie climácica de los sabinares litorales alternando con matorrales de Coremion albi, así como con los alcornocales psammófilos y pinos piñoneros del campo postdunar. La gran riqueza biológica de este sistema dunar radica en su enorme biodiversidad derivada, en parte, de su cercanía al Estrecho de Gibraltar, que le infiere características propias de los sistemas dunares atlánticos (con alcornoques) en un medio mediterráneo, haciéndolo único en la comunidad autónoma de Andalucía. Además, la fauna de este enclave es muy rica y variada, con numerosas especies protegidas y algunas, como el camaleón, en peligro de extinción (Gómez Zotano, 2009b). El interés natural de este espacio se complementa con la presencia de numerosos restos arqueológicos como unos baños romanos o dos torres vigías. La variedad y singularidad de estos ecosistemas litorales de Estepona, hacen pues, de éste, un espacio de alto valor eco-cultural, con una considerable diversidad biológica, geomorfológica y paisajística (Gómez Zotano, 2006, 2009b).

Pero esta estrecha franja también sufre la mayoría de los problemas ambientales que soporta buena parte de las costas andaluzas, todos ellos derivados del uso residencial y recreativo, por lo que el Saladillo-Matas Verdes, y en especial las frágiles dunas, sufren graves amenazas que ponen en peligro su conservación.

\section{RESULTADOS}

\subsection{Dinámica y evolución del sistema playa-duna a escala regional}

Considerando que el 59\% del litoral de Andalucía está urbanizado (Greenpeace, 2010), se entiende que los arenales litorales de esta comunidad autónoma, representados esencialmente por el sistema playaduna, hayan sufrido una pérdida significativa. De acuerdo con los datos extraídos de los mapas de usos y coberturas vegetales, en 1956 sumaban 9.484,4 has, extensión que respondía a un medio litoral en cierto equilibrio con la sociedad que lo habitaba, limitada, esta última, a ocupar aquellos espacios necesarios para el desarrollo urbano de los asentamientos más antiguos e importantes (Chipiona, Cádiz, Algeciras, La Línea, Estepona, Marbella, Fuengirola, Torremolinos, Málaga, Almuñécar, Adra o Almería). A partir de entonces, en tan solo 51 años, el progresivo desarrollo urbanístico, unido a la deficiente administración del suelo, al incremento poblacional y a la demanda turística, ocasionaron la pérdida o alteración de buena parte de los arenales litorales, viéndose disminuidos en un 34\% (3.217,3 has) en 2007. Actualmente se conservan $6.268,1$ has.

El análisis por vertientes permite contemplar marcadas diferencias entre la costa atlántica y la mediterránea, tanto en la configuración natural de los arenales, como en el grado de transformación antrópica (figura 3). La costa atlántica, baja y arenosa, comprende la mayor extensión de playas, dunas y arenales litorales andaluces, el $73,6 \%$ del total en 1956. En este año dichas formaciones naturales sumaban un total de $6.981,8$ has, viéndose reducidas en $2.503,9$ has en 2007 , una pérdida del 35,8\% equivalente a la suma de todos los arenales costeros de la vertiente mediterránea en 1956. Ésta última presenta unos arenales más modestos, pero ha sufrido, igualmente, un retroceso destacado: en 1956 la costa mediterránea comprendía el $26,4 \%$ de todos los arenales andaluces, con 2.503,8 has, superficie que se vio reducida a 1.790,3 has en 2007, lo que supone la desaparición del 28,5\% de la superficie inicialmente contemplada.

Los datos por provincias (figura 4) evidencian como la costa onubense conserva los arenales más extensos, concentrados en Doñana, si bien ha experimentado la mayor perdida superficial (1.821 has). Para explicar este retroceso del $34,9 \%$ cabe considerar, junto a las actuaciones antrópicas desarrolladas al amparo del planeamiento urbanístico, una importante dinámica litoral regresiva en playas como las de Isla Antilla, entre Isla Cristina y Lepe, el Alcor (Mazagón, Palos de la Frontera) y Matalascañas (Almonte). Los arenales de la provincia han sido ampliamente estudiados por García Novo et al. (1975), Vanney y Ménanteau (1979, 2004), Flor (1990), Rodríguez Vidal et al. (1993), Ménanteau (1994), Borja y Díaz del Olmo (1996), Dabrio et al. (1996), García Novo y Merino (1997), Bejarano Palma (1997), Borja et al. (1999), Borja y Barral (2002), Ojeda et al. (2002, 2005), Benavente et al. (2003), Zazo et al. (2005, 2011), Ménanteau et al. (2007), Vallejo y Ojeda (2007, 2011), Hernández y Vallejo (2008) y Rodríguez-Ramírez (2011). 
Figura 3. Superficie ocupada por playas, dunas y arenales entre 1956 y 2007 en Andalucía (por vertientes)

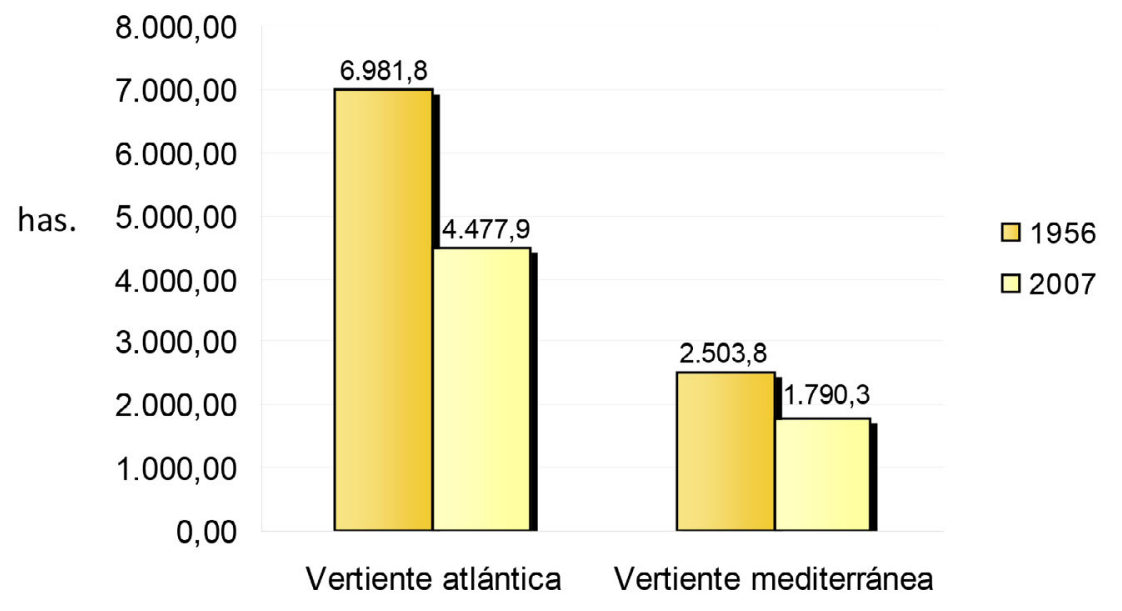

Fuente: "Mapas de usos y coberturas vegetales de Andalucía del año 1956 y 2007". Elaboración propia

La provincia de Cádiz posee la segunda mayor extensión superficial de arenales litorales andaluces. En 1956 alcanzaban 2.213,2 has, destacando las playas y dunas de Bolonia y San Roque. Desde entonces, y hasta 2007, ha experimentado una importante pérdida generalizada, el 38,7\% del total provincial (858,1 has), aunque con significativas excepciones de dunas progradantes (Bolonia y Valdevaqueros). Entre los sistemas playas-dunas más perturbados destacan Media Lengua, Jara y Montijo, entre Sanlúcar de Barrameda y Chipiona; Tres Piedras en Chipiona; Ballena en Rota; Fuentebravía, Santa Catalina y Valdelagrana en el Puerto de Santa María; La Barrosa en Chiclana de la Frontera; El Palmar en Vejer de la Frontera y Caños de Meca en Barbate. Esta dinámica regresiva también ha afectado a la costa mediterránea de la provincia, en concreto a playas como Getares en Algeciras, la Atunara en la Línea de la Concepción, o Sotogrande en San Roque. La tipología y dinámica de los arenales gaditanos han sido analizadas por García Mora et al. (2001), Gómez Pina et al. (2002, 2006, 2007), Benavente et al. (2003, 2005), Anfuso (2004), Arteaga y González (2004), Román Sierra et al. (2004), Gracia et al. (2006), Ministerio de Medio Ambiente (2006), Navarro et al. (2007), Muñoz Pérez et al (2009) y Gracia Prieto et al. (2011).

Figura 4. Distribución por provincias de la superficie ocupada por playas, dunas y arenales entre 1956 y 2007

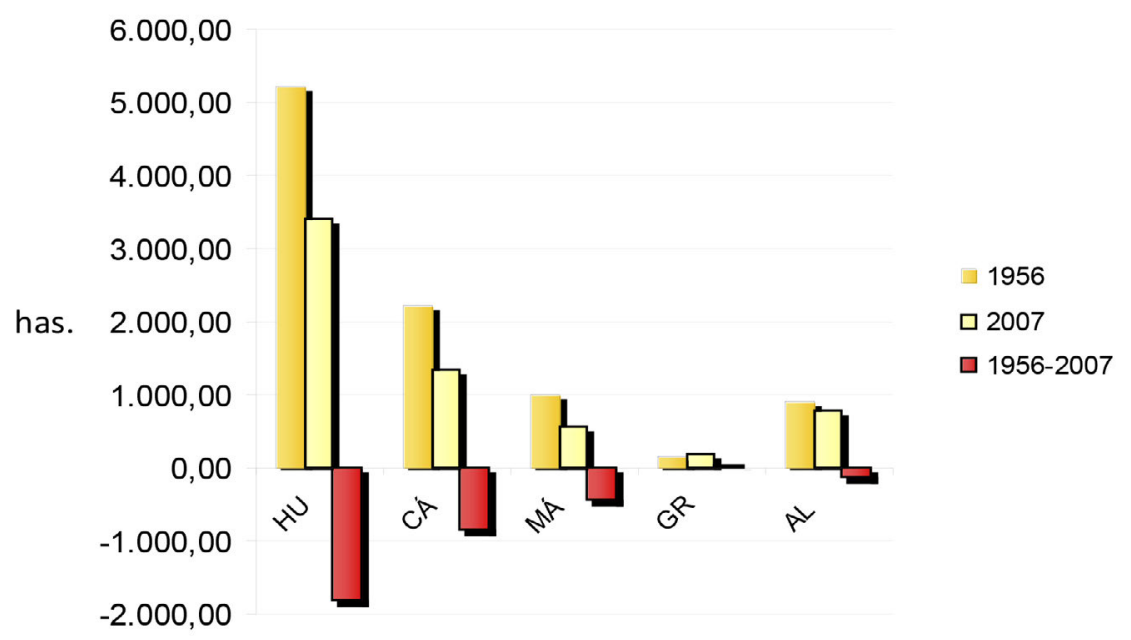

\begin{tabular}{|c|c|c|c|c|c|c|}
\hline Año/has & HU (Huelva) & CÁ (Cádiz) & MÁ (Málaga) & GR (Granada) & AL (Almería) & Andalucía \\
\hline 1956 & $5.215,3$ & $2.213,2$ & 998,7 & 160,2 & 898,1 & $9.484,4$ \\
\hline 2007 & $3.394,3$ & $1.355,1$ & 559,2 & 176,6 & 782,9 & $6.268,1$ \\
\hline $1956-2007$ & $-1.821,0$ & $-858,1$ & $-449,5$ & $+16,4$ & $-115,2$ & $-3.217,3$ \\
\hline
\end{tabular}

Fuente: "Mapas de usos y coberturas vegetales de Andalucía del año 1956 y 2007". Elaboración propia 
En el Mediterráneo, además de las correspondientes playas gaditanas, las provincias de Málaga, Granada y Almería ofrecen situaciones muy distintas. La malagueña Costa del Sol, núcleo original del turismo de sol y playa en Andalucía, ha sufrido la mayor pérdida relativa (el 45\%), habiéndose reducido considerablemente la superficie de sus arenales: los "barronales" formaban un ecosistema continuo, hoy perdido, que se extendía de oeste a este por playas como las del Gobernador, Tubalitas, del Negro y de Sabinillas en Manilva; Playa Ancha en Casares; Buenas Noches, Arroyo Vaquero, Guadalobón, Punta Plata, Velerín, Guadalmansa, Saladillo y Casasola en Estepona; Guadalmina, San Pedro de Alcántara, y litoral que se desarrolla entre Río Verde y Punta Ladrones (playa Alicate, de Las Chapas, de Cabopino, etc.) en Marbella; La Cala en Mijas; Playa del Castillo en Fuengirola; La Carihuela o el Bajondillo en Torremolinos y Rincón de la Victoria, Ferrara y Peñoncillo en Torrox. Algunos de estos edificios dunares costeros han sido estudiados por Málvarez et al. (1998), Gómez Zotano (2006, 2007, 2009b) y Bardají et al. (2011).

La provincia de Granada es la única que ha experimentado un aumento de la superficie ocupada por playas, dunas y arenales. La explicación hay que buscarla, igualmente, en las actuaciones antrópicas; la construcción de espigones en playas como las de Almuñécar ha posibilitado una considerable progresión de las arenas. Asimismo, la deficiente fotointerpretación del vuelo americano de 1956 en la fuente utilizada, donde se obvian las amplias playas del delta del río Gualdafeo, distorsiona los resultados finales. En cualquier caso, la naturaleza de las playas granadinas, cerradas, ha favorecido la estabilidad natural de las mismas, si bien ha habido una degradación importante, especialmente en sus mermados ecosistemas dunares (playa de la Charca en Salobreña, y de Poniente, de las Azucenas y de Carchuna en Motril). En este sentido, el litoral de Granada ha sido objeto de estudio en Lario et al. (1999), Ortega Sánchez et al. (2003), Gómez Zotano (2009a) y Gómez Zotano et al. (2009).

La provincia de Almería ha perdido 115,2 has de arenales costeros, el descenso menos acusado de todas las provincias andaluzas en el periodo analizado. No obstante, la acción conjugada de la urbanización y los cultivos intensivos bajo plástico ha afectado a importantes cordones dunares como los de las Albuferas (Adra), Balanegra (Berja), Balerma, San Miguel-Punta Entinas (El Ejido), Cerrillos, Serena y Aguadulce (Roquetas de Mar), Retamar (Almería) o la playa de Garrucha. La dinámica y características de los complejos dunares almerienses han sido analizadas por Dabrio et al. (1984), Viciana (2001), Paracuellos (2006), Viciana et al. (2006), Lores Calero (2007), López Martos et al. (2010) y Bardají et al. (2011).

Lejos de lo que se pudiera pensar, la dinámica regresiva de los sistemas playa-duna andaluces continua en la actualidad; como se observa en la figura 5, el urbanismo expansivo sigue siendo una amenaza para los complejos dunares, poniendo en peligro su conservación en todas las provincias, tanto por haberse iniciado el proceso de desarrollo urbanístico (son 10 los casos más recientes de ejecución de Plan Parcial), como por amenaza de desarrollo inminente de un proyecto de urbanización (son dos los complejos dunares que presentan aprobación de Plan Parcial en diferentes fases, uno en Tarifa y otro en Estepona).

Figura 5. Identificación y localización de los ecosistemas dunares andaluces afectados por actuales procesos de urbanización

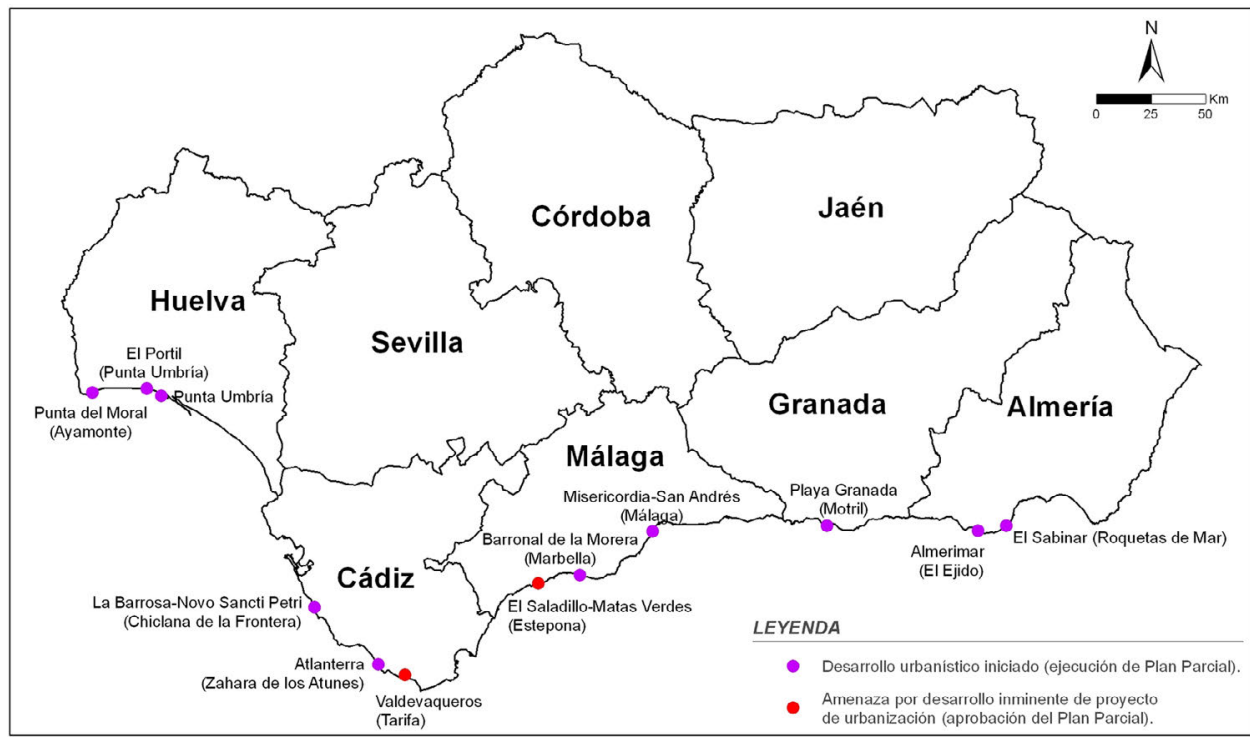

Fuente: Instituto de Cartografía de Andalucía. Elaboración propia 
En la costa atlántica, en la provincia de Huelva, el desarrollo urbanístico y las construcciones ilegales han provocado un importante deterioro de los sistemas dunares de la Punta del Moral, en Isla Canela (Ayamonte), o El Portil de Punta Umbría. En Cádiz, en la playa de La Barrosa-Novo Sancti Petri (Chiclana de la Frontera), se han sepultado cordones dunares, talado pinares y eliminado diversos ejemplares de especies vegetales de gran valor como el enebro marítimo y la camarina, con alteración irreversible de su hábitat. En la playa de Zahara de los Atunes, en Barbate, las edificaciones desmesuradas de la urbanización Atlanterra han ocupado, ilegalmente, suelo no clasificado como urbano en el Plan General de Ordenación Urbana (PGOU), y han destruido cordones dunares de alto interés ecológico. La última amenaza en la provincia gaditana se cierne sobre los extensos arenales de Valdevaqueros y su entorno paisajístico: se trata de la aprobación definitiva del "Plan Parcial de Ordenación del Sector SL-1 Valdevaqueros" el 29 de mayo de 2012 por parte del Pleno del Ayuntamiento de Tarifa, un controvertido plan urbanístico que prevé levantar 1.400 plazas hoteleras y 350 viviendas en un enclave célebre por constituir uno de los pocos tramos costeros europeos libres de urbanización (figura 6).

Figura 6. Proyecto de urbanización del Sector SL-1 Valdevaqueros

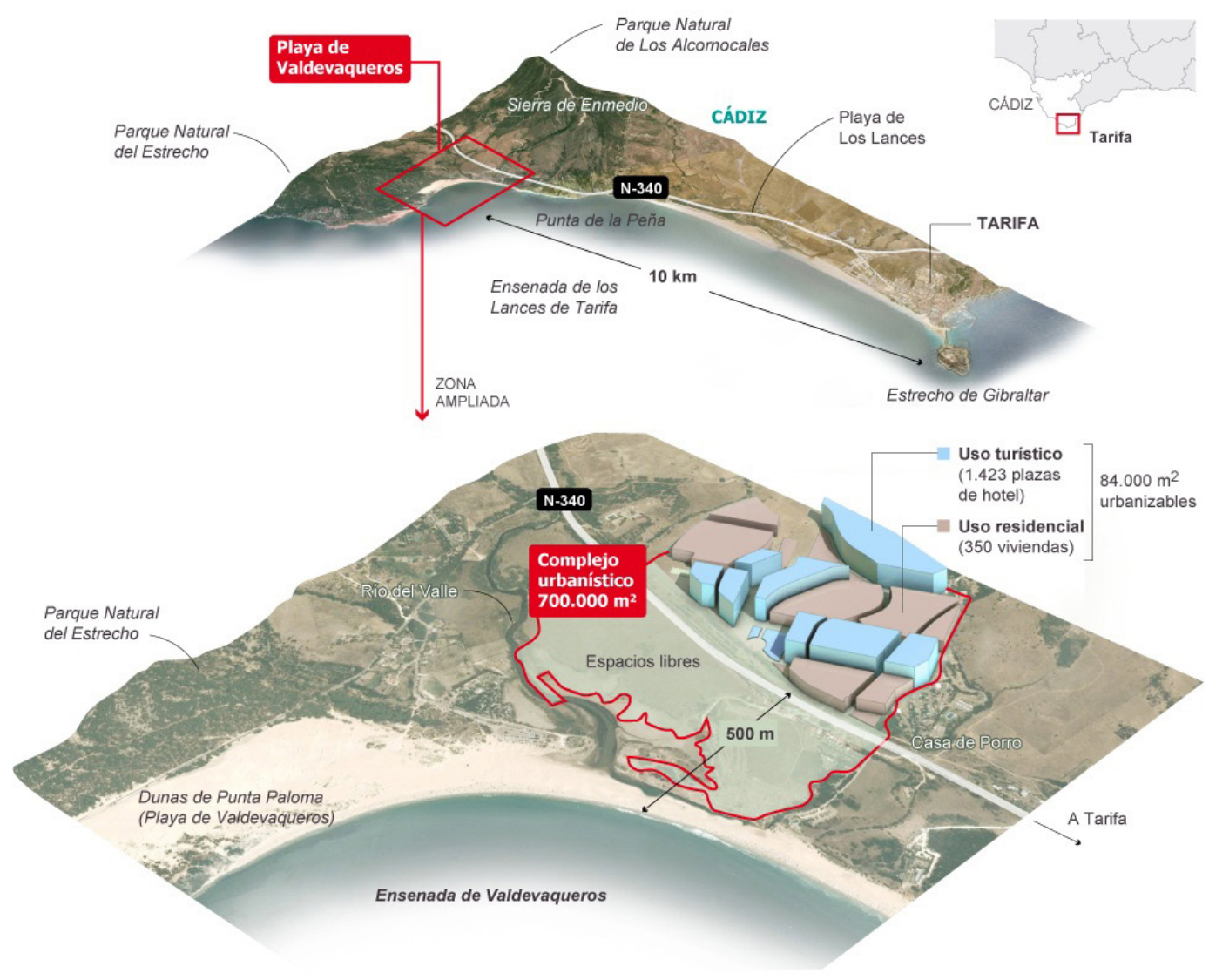

Fuente: Mariano Zafra, Diario El País, 1 de junio de 2012

En la costa mediterránea, en la provincia de Málaga, las dunas del Saladillo-Matas Verdes (Estepona) constituyen el segundo caso, menos mediático, de valiosos ecosistemas dunares andaluces amenazados por desarrollo inminente de proyecto de urbanización. Este complejo dunar sigue catalogado como suelo urbanizable en el PGOU municipal de 1994, habiéndose aprobado inicialmente el Plan Parcial "SUB-E8 Playa de Baños" (con fecha 24 de noviembre de 2011), para la construcción de un complejo hotelero más. En Marbella, las playas de los Monteros, Las Chapas y Real de Zaragoza están siendo sometidas a una masificación urbanística pese a la ampliación de la zona de dominio público marítimo terrestre, y se ha procedido recientemente a la eliminación de extensos complejos dunares como el Barronal de la Morera. En la ciudad de Málaga las modestas dunas de las playas de la Misericordia y de San Andrés están siendo subsumidas en el continuo urbano. En Granada destaca la urbanización Playa Granada de Motril y en Almería Almerimar (El Ejido), complejo turístico construido sobre los extensos arenales de la 
playa de San Miguel, continuación de los de Punta Entinas, así como el complejo Vereda Golf, expansión urbanística de Roquetas de Mar hacia las dunas del Sabinar.

\subsection{Dinámica y evolución del sistema playa-duna a escala local}

\subsubsection{Evolución histórica}

El complejo dunar Saladillo-Matas Verdes, objeto de estudio más detallado, se integra en una franja litoral que ha conocido una temprana e intensa ocupación humana (Gómez Zotano, 2006). A partir de la segunda mitad del siglo XX, no obstante, los usos tradicionales ligados a los "barronales" (ganadería, pesca, defensa) quedan minimizados por el urbanismo expansivo asociado al turismo de masas. Esta nueva actividad supuso la desaparición de amplísimos sectores de los arenales, la colmatación de marismas y humedales asociados, el encauzamiento de ríos y arroyos, o la modificación de la línea de costa y de los fondos marinos (Gómez Zotano, 2009b); actuaciones y efectos vigentes en la actualidad.

El proceso urbanizador se inició efectivamente con la construcción del Hotel Santa Marta en 1951. A partir de entonces, éste centralizó a su alrededor un buen número de promociones urbanísticas y residencias aisladas, al igual que sucediera en otros enclaves de la recién creada Costa del Sol. En las décadas de los 60 y 70 el cordón dunar se vio reducido a unos pocos restos de dunas aisladas entre casas y apartamentos. Aunque existían razones jurídicas y técnicas para considerar las dunas como parte integrante de las playas, lo cierto es que, al no estar expresamente incluidas en la definición de los bienes de dominio público marítimo terrestre por la Ley de Puertos de 1928 o la de Costas de 1969, quedaron fuera de los deslindes aprobados entonces, como la mayor parte de las dunas andaluzas. Consecuentemente, este ha sido el periodo en el que se han registrado los cambios más drásticos del paisaje litoral del municipio de Estepona.

A principios de los años 60 se asiste a la progresiva aprobación de numerosos proyectos de construcción de hoteles y urbanizaciones que, como el Hotel Atalaya Park o las urbanizaciones Saladillo, Casasola, Isdabe, El Barronal, Benamara o Villacana, paulatinamente van ocupando el tramo costero en cuestión hasta finales de los 70 (figura 7). En los años 80, una nueva oleada de urbanizaciones irá completando las parcelas urbanizables restantes hasta entonces. La entrada en vigor de la Ley de Costas en 1988 no pudo evitar que se continuaran destruyendo los arenales costeros. Al margen de dicha Ley, la consolidación de las urbanizaciones anteriormente citadas continuó junto a la construcción de otras nuevas, entre las que destaca, por su magnitud y trascendencia territorial, "El Presidente"; este complejo urbanístico se levantó sobre las dunas más occidentales de la playa de Casasola, junto a la Punta de Dos Hermanas, y entre extensas repoblaciones de pino piñonero efectuadas varios años antes.

Figura 7. Inicios de la Urbanización Saladillo (Estepona) hacia 1962. Los barronales que respaldaban esta extensa playa se verían abocados a su desaparición a partir de entonces

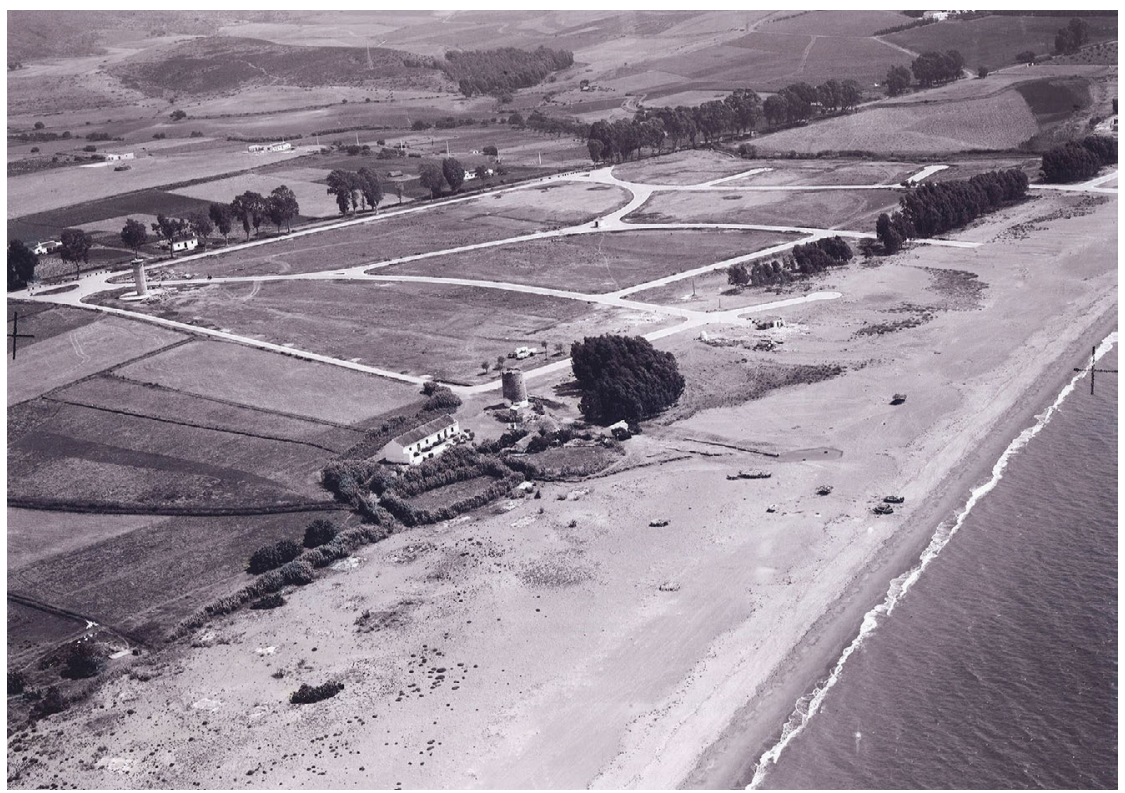

Foto: Paisajes Españoles 
A partir de 1995, coincidiendo con el fin de la crisis que desde 1992 sacudió los cimientos del modelo desarrollista predominante en la Costa del Sol, el sector Saladillo-Matas Verdes experimenta la última pulsación que transformará su paisaje en lo que es actualmente, un continuo urbano con escasos restos de ecosistemas naturales. Persiste la tónica de la etapa precedente y se ocupan los escasos solares que restan entre las urbanizaciones existentes. Así ha ocurrido con la construcción de promociones urbanísticas recientes como Costalita o Matas Verdes, u hoteles como Marriott's Playa Andaluza que, además han tenido un fuerte impacto ambiental al desmantelar varios restos dunares. La construcción de paseos marítimos, jardines, chiringuitos, caminos, aparcamientos, red de saneamiento y un largo etc., se suma a la ya amplia lista de impactos.

La mayor parte de las dunas son de titularidad privada. Las principales parcelas (Punta del Saladillo y Matas Verdes) pertenecen al mismo propietario, la reconocida familia alemana Opel, un dato relevante si se considera que la conservación de estos arenales desde los años 50 del siglo XX ha sido posible gracias a la iniciativa de sus propietarios (Gómez Zotano, 2009b). Hoy día, sin embargo, son éstos quienes apuestan por dar otra orientación a sus parcelas amparados en el vigente PGOU municipal, que mantiene, pese a las numerosas alegaciones recibidas, una calificación del suelo como urbanizable. Si bien dicho plan no ha sido adaptado al POTA, y la calificación se ve reforzada por las directrices del Plan Subregional de Ordenación del Territorio de la Costa del Sol Occidental, el nuevo Plan de Protección del Corredor Litoral de Andalucía, pendiente de aprobación, reconoce el valor ambiental de parte del cordón dunar (Protección Territorial PT2: MA-S5, SURS-E8 Playa Baños). Responde así, aunque de manera insuficiente, al movimiento ciudadano que demanda, desde inicios del siglo XXI, la protección del conjunto de los valiosos restos dunares de Estepona (Gómez Zotano, 2009b).

El gráfico de la figura 8 permite visualizar el proceso urbanizador del territorio hasta ahora descrito. En 1956 los usos urbanos no alcanzaban la hectárea de terreno. Concentrados en el pionero Hotel Santa Marta, éstos no suponían más del 0,2\% del total del ámbito de estudio. En 1977, en cambio, el boom turístico conllevó un incremento del uso urbano en casi 90 has, lo que suponía un porcentaje considerable respecto a la superficie total del ámbito $(28,47 \%)$. El crecimiento exponencial de la urbanización continuó durante las dos décadas siguientes y, en 1994, las urbanizaciones ocupaban algo más de la mitad del suelo $(56,4 \%)$, con 177,5 has. Finalmente, en 2007 , las edificaciones alcanzaban el 75,57\% del total del sector costero con 237,8 has de las 314,67 que suma el conjunto.

Figura 8. Evolución de la superficie edificada en el sector costero Saladillo-Matas Verdes (1956-2007)

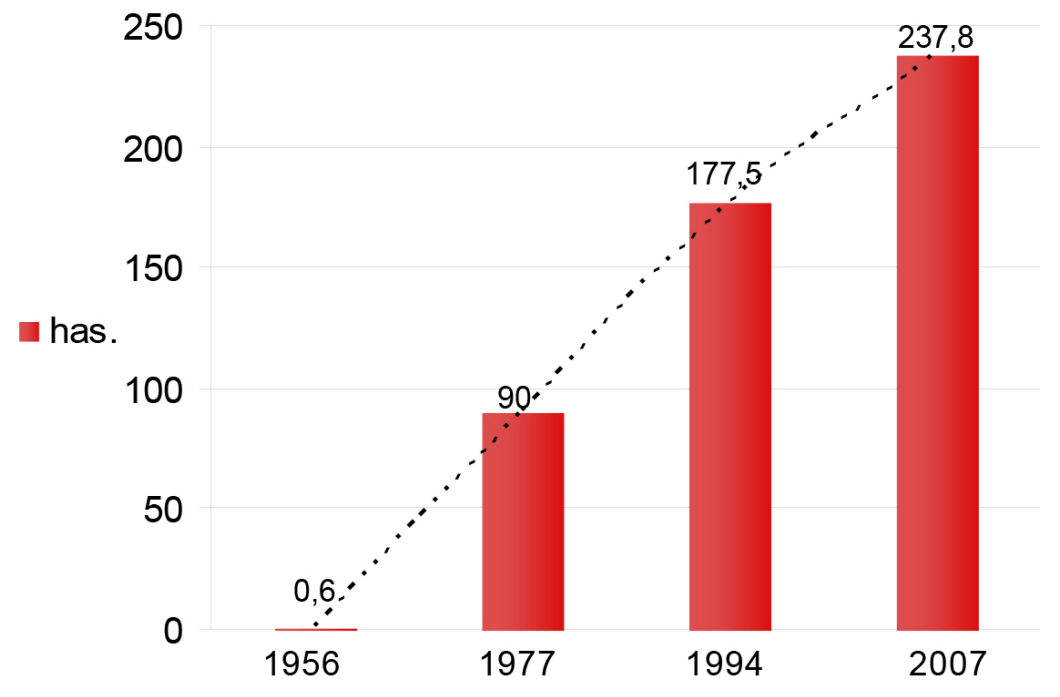

Fuente: elaboración propia a partir de la interpretación de imágenes aéreas (1956-2007)

\subsubsection{Dinámica espacial}

La progresión continua del proceso urbanizador ha supuesto que las dunas del Saladillo-Matas Verdes experimenten una dinámica espacial regresiva, pasando de tener una anchura de $300 \mathrm{~m}$ de media, a redu- 
cirse, en el mejor de los casos, a dos centenas de metros y, en el peor de los casos, a desaparecer. En 1956 el sistema playa-duna ocupaba 69,5 has. En 1977, este sistema disminuyó drásticamente su extensión y pasó a tener 40 has. Hasta el año 1994 las dunas y playas se vieron menos afectadas por la urbanización que en los años precedentes y se quedaron reducidas a 38,55 has. En 2007, las 31,07 has sumadas por estos arenales litorales evidencian una merma importante en los últimos años (figuras 9, 10 y 11).

Figura 9. Regresión de los arenales costeros (1956-2007) del tramo litoral Saladillo-Matas Verdes
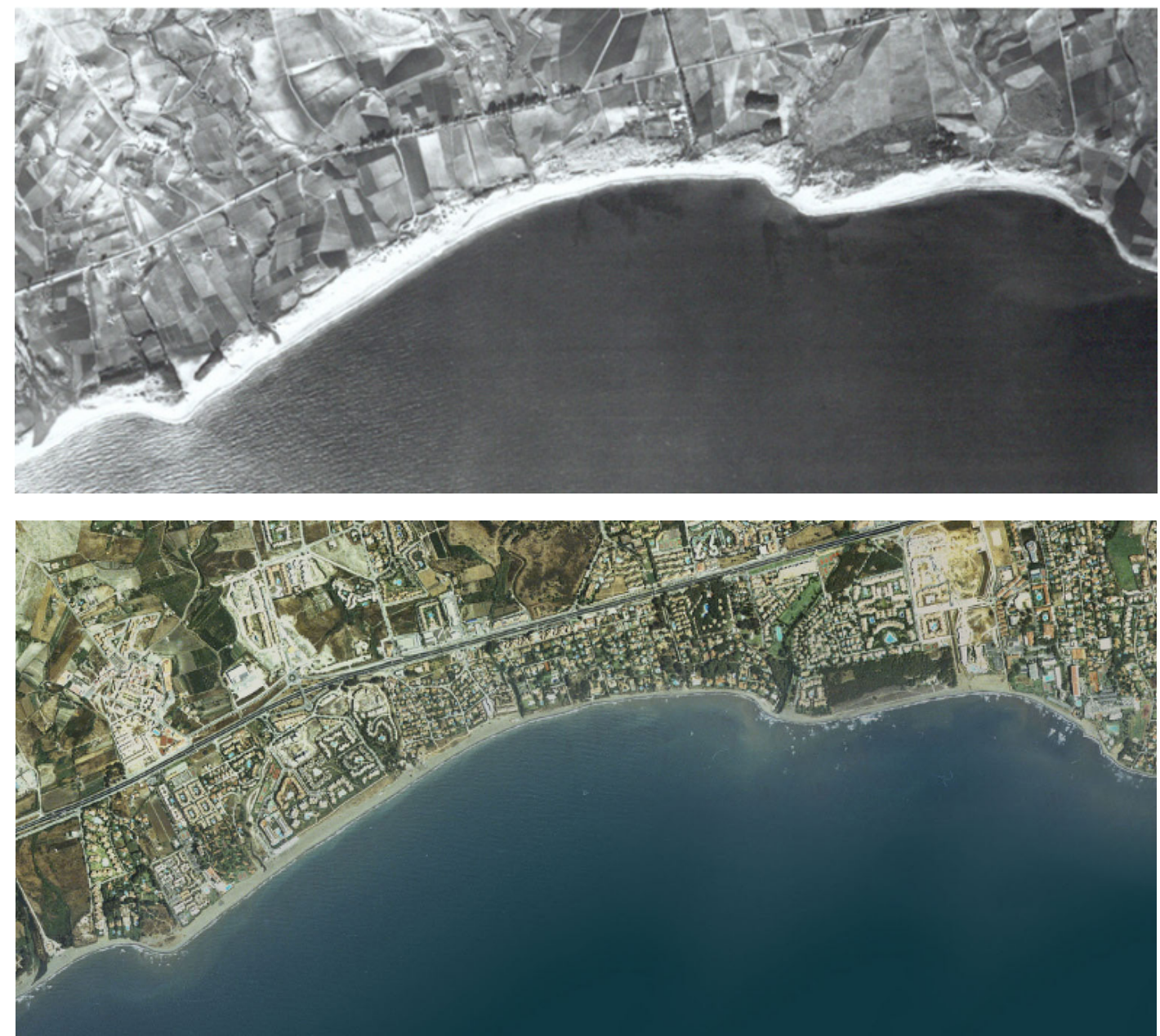

Fuente: Vuelo americano (1956); vuelo de la Junta de Andalucía (2007)

Figura 10. Dinámica del sistema playa-duna del Saladillo-Matas Verdes

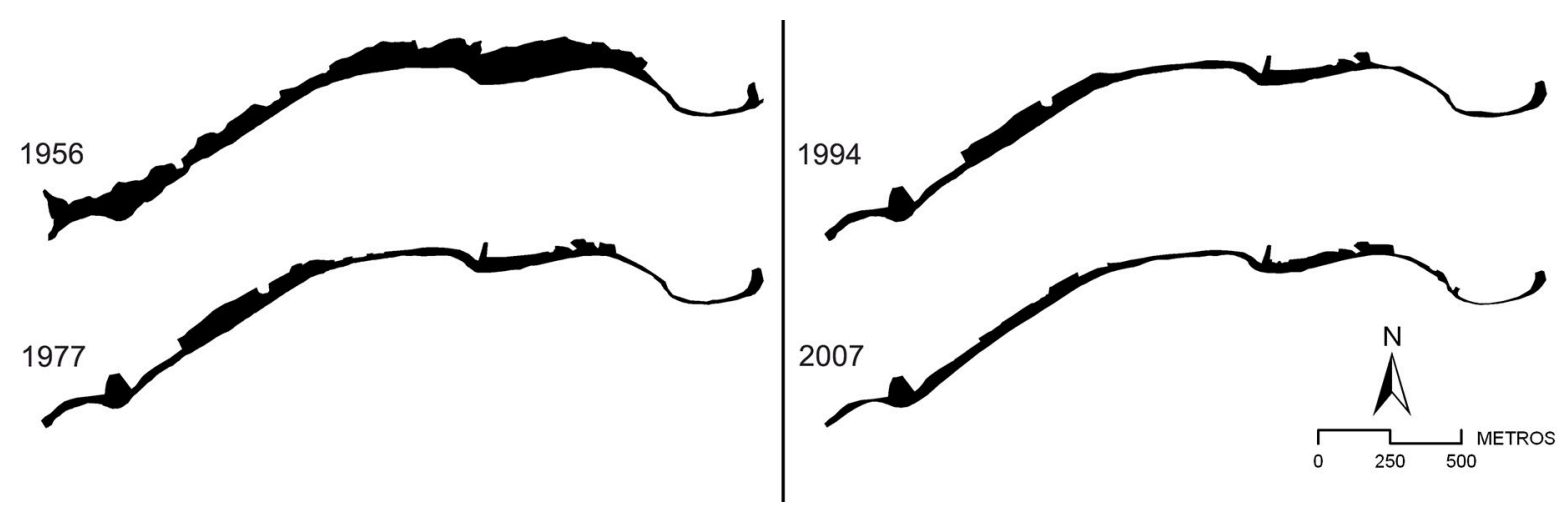

Fuente: Vuelos americano (1956), del Ministerio de Agricultura (1977) y de la Junta de Andalucía (1994, 2007). Elaboración propia 
Figura 11. Detalle de la degradación experimentada por las dunas de Matas Verdes. Arenales y repoblaciones de pinos piñoneros son sustituidos por urbanizaciones como El Presidente o Marriott's, que actualmente rodean la parcela propiedad de la familia Opel
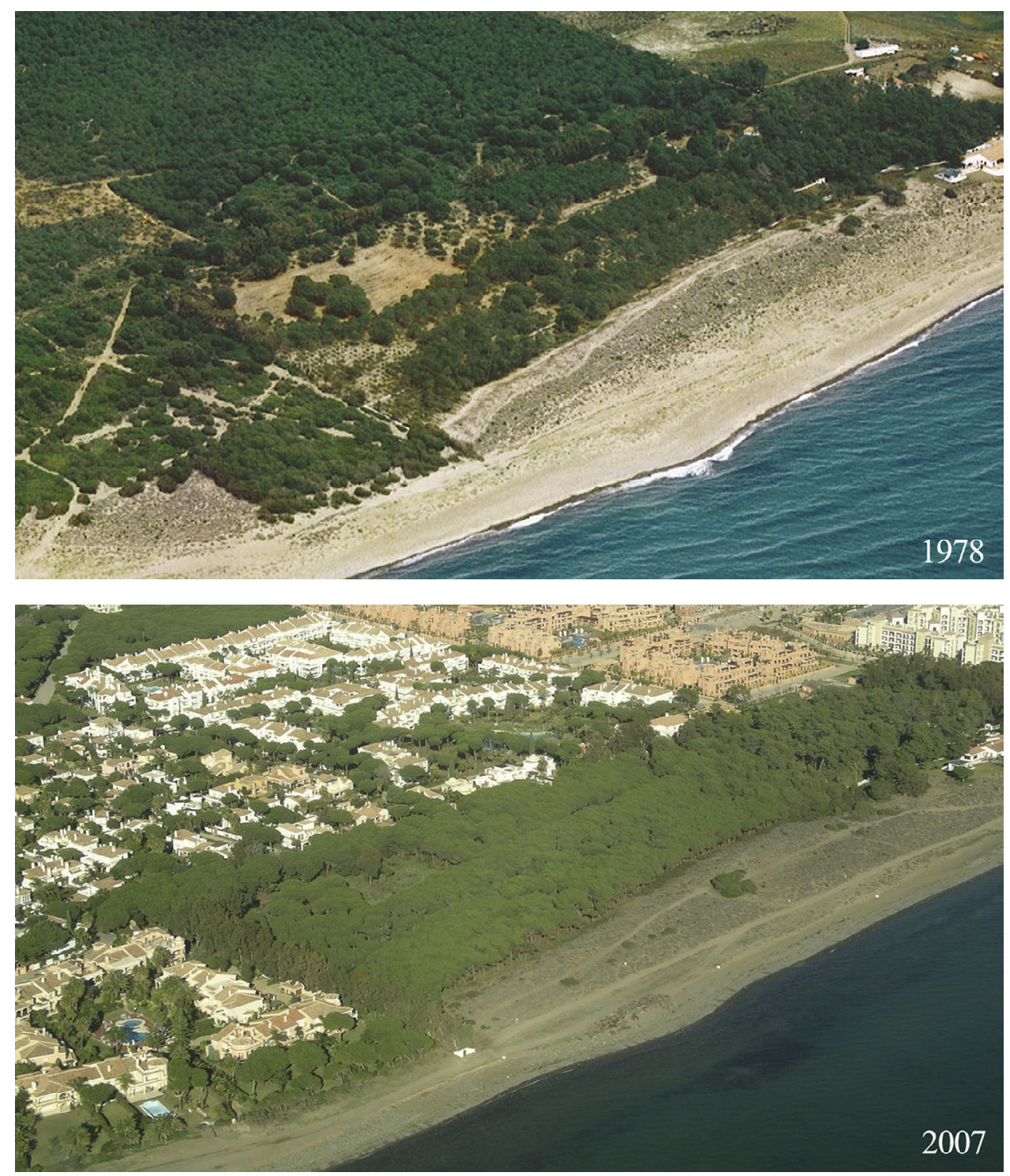

Foto 1978: Paisajes Españoles; Foto 2007: José Gómez Zotano

En la actualidad, las dunas analizadas representan un $44,7 \%$ de la superficie existente hace medio siglo, a favor de la urbanización, que ocupa ya más del 70\% del tramo costero analizado; la construcción de reconocidas urbanizaciones ha fragmentado el complejo dunar en tres tramos diferentes y de desigual desarrollo. De oeste a este se encuentran las dunas de la playa de Guadalmansa y la Punta del Saladillo que, pese a estar relegadas a una parcela y presentar claros indicios de degradación, mantienen intacto su potencial ecológico. En el centro del conjunto permanecen las dunas del Saladillo (Playa del Saladillo), desmanteladas en buena parte (sólo quedan las dunas primarias y secundarias). Finalmente, en la Playa de Casasola se desarrollan las dunas de Matas Verdes, que, rodeadas por la urbanización, presentan un precario estado de conservación tal y como se puede observar en la figura precedente.

\section{DISCUSIÓN}

Los resultados del análisis multitemporal realizado en esta investigación permiten cuantificar la extensión superficial de los sistemas playa-duna en Andalucía entre 1956 y 2007, constatando que, desde los años 50 del siglo XX, han sido dilapidados numerosos arenales atlánticos y mediterráneos. 
Desde la perspectiva espacial, la aproximación interescalar facilita, por primera vez, una visión de conjunto del fenómeno analizado. Cabe recordar que la mayoría de los estudios publicados proporcionan un conocimiento sectorial y detallado de las características físico-naturales y de la evolución reciente de distintos sistemas playa-duna de Andalucía.

Por su parte, la aplicación de las diferentes técnicas de análisis espacio-temporal, posibilita que los resultados sean expresados tanto de forma estadística, como de forma cartográfica, e implementados en distintas bases de datos, permitiendo al planificador y gestor un conocimiento geográfico sobre el litoral a distintas escalas espacio-temporales.

En relación con la gestión del territorio, se exponen contradicciones y conflictos de una organización espacial, pasada y actual, basada en el urbanismo expansivo en sentido amplio. Ello invita a reflexionar sobre la necesidad de establecer un nuevo equilibrio derivado de una gestión integrada, como instrumento de protección ambiental y de asignación de un uso sostenible al territorio, frente a las potenciales actuaciones antrópicas generadoras de impacto. Dicha política pública debe encontrar respuestas a problemas bien definidos que afectan, en gran medida, a bienes e intereses de naturaleza pública (revisión escrupulosa de los límites del Dominio Público Marítimo Terrestre, aplicación estricta de la legislación vigente, revisión del planeamiento municipal, etc.).

De acuerdo con Ojeda et al. (2013), el mantenimiento del sistema playa-duna resulta crucial en el análisis de la sensibilidad a la pérdida de las playas como recurso turístico en Andalucía. Los autores afirman que la presencia de dunas costeras garantiza una protección de la playa frente a la erosión proporcional a su extensión (dunas extensas $>130 \mathrm{~m}$; medias 30-130 m y pequeñas $<30 \mathrm{~m}$ ). En consecuencia, la gestión integrada del espacio litoral se presenta como una necesidad, atendiendo no sólo a motivos estrictamente ecológicos o culturales, suficientes ya en sí mismos, sino también a causas socioeconómicas, por cuanto supone el soporte de numerosas actividades productivas y el lugar de residencia de un importante porcentaje de la población andaluza.

Queda por ver si la puesta en marcha de la Estrategia Andaluza de Gestión Integrada de Zonas Costeras, el recién aprobado Proyecto de Ley de Protección y Uso Sostenible del Litoral y de modificación de la Ley de Costas de 1988, o el Plan de Protección del Corredor Litoral de Andalucía, suponen un nuevo instrumento para la toma de decisiones que facilite el tránsito hacia un desarrollo más sostenible. La mejora de la gestión de las zonas costeras andaluzas, y de sus recursos, constituye un marco oportuno que permite contemplar la posibilidad real de que los complejos dunares actualmente desprotegidos sean conservados, y los deteriorados recuperados.

\section{CONCLUSIONES}

En el presente artículo se ha obtenido una visión de conjunto inédita del proceso urbanizador de dunas litorales en Andalucía, así como un ejemplo particular extrapolable a cualquier otro caso de sistema playaduna amenazado en este territorio. El análisis evolutivo y multiescalar, basado en las fuentes cartográficas, resulta pertinente a la luz de los recientes conflictos de intereses que se desarrollan en el litoral de España en general, y de Andalucía en particular (Valdevaqueros o Saladillo-Matas Verdes por ejemplo). Aporta datos objetivos a la dimensión social del problema y contribuye al debate, necesario, sobre el modelo de desarrollo contemporáneo -obsoleto para muchos-, que se aferra con fuerza para no desaparecer en los actuales momentos de incertidumbre ambiental, social y económica.

A poco que se examinen los resultados del análisis presentado, no puede sino meridianamente concluirse, que la desaparición de dunas litorales en Andalucía es resultado de una presión ocupacional continua y progresiva, acompañada de un proceso urbanizador que se detiene, únicamente, para mantener libres aquellos espacios estrictamente necesarios para el uso de las playas, sin considerar que ambos sistemas -dunas y playas- son interdependientes. Se puede hablar, por tanto, del relativo fracaso que ha supuesto la aplicación de las distintas políticas y figuras de ordenación y planificación del litoral a todos los niveles; a pesar de los logros conseguidos en el ámbito de la conservación, el litoral es un sistema complejo, y su preservación no puede entenderse como la suma de espacios protegidos inconexos. La corrección de esta visión territorial sesgada debe aglutinar todos los esfuerzos relativos a la gestión del litoral en el futuro inmediato.

Proceder a la salvaguarda de los sistemas playa-duna implica mantener su plena funcionalidad ecológica, y tratar de restaurar y recuperar aquellos que han desaparecido o han sido gravemente alterados. La existencia de las playas andaluzas depende de ello. 


\section{AGRADECIMIENTOS}

El presente trabajo se ha desarrollado en el marco del proyecto financiado por la Obra Social de la Fundación la Caixa (2005-APM) "Reconocimiento biofísico de un sector costero con posibilidad de ser reserva marítimo-terrestre".

\section{BIBLIOGRAFÍA}

ANFUSO, G. (2004): "Caracterización de celdas litorales en un tramo costero aparentemente homogéneo del litoral de Cádiz (SO de España)", Cuaternario y Geomorfología, 18 (1-2), 25-36 pp.

ARTEAGA, C. y GONZÁLEZ MARTÍN, J.A. (2004): "Presencia de materiales marinos y dunares sobre un alfar romano en la Bahía de Algeciras (Cádiz, España)", en: Benito G., Díez Herrero A. (eds.), Contribuciones recientes sobre Geomorfología. Actas VIII Reun. Nac. Geomorfología, Toledo, C.S.I.C.S.E.G., Vol. I, 393-400 pp.

BARDAJÍ, T., ZAZO, C., LARIO, J., GOY, J.L., CABERO, A., DABRIO, C.J. Y SILVA, P.G. (2011): "Las dunas costeras del Presente y Último Interglaciar en Málaga, Almería y Murcia", en: Sanjaume Saumell E.; Gracia Prieto FJ. (eds.) Las dunas en España. Sociedad Española de Geomorfología, 331-357 pp.

BEJARANO PALMA, R. (1997): Vegetación y paisaje en la costa atlántica de Andalucía. Universidad de Sevilla. Sevilla.

BENAVENTE, J., DEL RÍO, L., GRACIA, FJ. y ANFUSO, G. (2003): "Cuantificación de procesos de erosión costera en el litoral sur atlántico español. Primeros resultados", Geogaceta, 33, 3-6 pp.

BENAVENTE, J.; GRACIA, FJ.; DEL RÍO, L. y ANFUSO, G. (2005): "Morfologías dunares en la costa atlántica gaditana: evolución histórica y estado actual", en: Hernández L.; Alonso I.; Mangas J.; Yanes A. (eds.) Tendencias actuales en Geomorfología Litoral. Actas de las III Jornadas de Geomorfología Litoral. Serv. Publ. Univ. Las Palmas de Gran Canaria, 97-100 pp.

BORJA, F. y DÍAZ DEL OLMO, F. (1996). "Manto eólico litoral (MEL) del Abalario (Huelva, España): Episodios morfogenéticos posteriores al 22.000 BP", en: Pérez Alberdi A.; Martini A.P.; Chessworth W.; Martínez Cortizas A. (eds.) Dinámica y Evolución de Medios Cuaternarios. Xunta de Galicia, Santiago de Compostela, 375-390 pp.

BORJA, F., ZAZO, C., DABRIO, C.J., DÍAZ DEL OLMO, F., GOY, J.L y JAVIER, L. (1999): "Holocene aeolian phases and human settlements along the Atlantic coast of southern Spain", The Holocene, 9 (3), 333-339 pp.

BORJA, F. y BARRAL, M.A. (2002): "Análisis sedimentario y caracterización morfodinámica del sector oriental del manto eólico litoral de El Abalario-Doñana (Parque Nacional de Doñana)", en: PérezGonzález, A.; Vegas, J.; Machado, J. (eds.), Aportaciones a la Geomorfología de España en el inicio del tercer milenio. Publicaciones IGME, Serie Geología, 1, 159-165 pp.

BROWN, A.C. y MCLACHLAN, A. (1990): Ecology of Sandy shores. Elsevier. Amsterdam.

BROWN, A.C. y MCLACHLAN, A. (2002): "Sandy shore ecosystems and the threats facing them: some predictions for the year 2025", Environmental Conservation, 29 (1), 62-77 pp.

MÉNANTEAU, L., CHADENAS, C. y CHOBLET, C. (2007): "Les marais du bas-Guadiana (Algarve, Andalousie): emprise, déprise et reprise humaines", Aestuaria, 9, 309-331 pp.

DABRIO, C., GOY, J.L. y ZAZO, C. (1984): "Dinámica Litoral y Ambientes Sedimentarios en el Golfo de Almería desde el Tirreniense a la Actualidad", en I Congreso Español de Geología, Tomo I, 507-522 pp.

DABRIO, C.J., BORJA, F, ZAZO, C., BOERSMA, R.J., LARIO, J., GOY, J.L. y POLO, M.D., (1996): "Dunas eólicas y facies asociadas pleistocenas y holocenas en el acantilado de El Asperillo (Huelva)", Geogaceta, 20, 1089-1092 pp.

EUROPEAN ENVIRONMENTAL AGENCY (2006): "The changing faces of Europe's coastal areas", EEA Rep., 6.

FLOR, G. (1990): "Tipología de las dunas eólicas. Procesos de erosión-sedimentación costera y evolución litoral de la provincia de Huelva (Golfo de Cádiz occidental, Sur de España)", Estudios Geológicos, 46, 99-109 pp.

GARCÍA MORA, M.R., GALLEGO FERNÁNDEZ, J.B., WILLIAMS, A.T. y GARCÍA NOVO, F.A. (2001): "Coastal dune vulnerability classification. A case study of SW Iberian Peninsula", Journal of Coastal Research, 17 (4), 802-811 pp.

GARCÍA-NOVO, F., RAMÍREZ-DÍAZ, L. y TORRES-MARTÍNEZ, A. (1975): "El sistema de dunas de Doñana", Naturalia Hispanica, 5, p. 56. 
GARCÍA NOVO, F. y MERINO, J. (1997): "Pattern and process in the dune system of the Doñana National Park", Ecosystems of the world: Dry coastal ecosystems, Elsevier, 2c, 453-468 pp.

GARRIDO CUMBRERA, M. y LÓPEZ LARA, E. (2010): "Consecuencias del turismo de masas en el litoral de Andalucía (España)", Cuaderno Virtual de Turismo, 10 (1), 125-135 pp.

GÓMEZ PINA, G., MUÑOZ PÉREZ, J.J., RAMÍREZ, J.L. y LEY, C. (2002): "Sand dune Management problems and techniques, Spain", Journal of Coastal Research, 36, 325-332 pp.

GÓMEZ-PINA, G., FAGES, L., RAMÍREZ, J.L., MUÑOZ-PÉREZ, J.J. y ENRÍQUEZ, J. (2006): “A critical review of beach restoration projects in the northern coast of Cadiz (Spain) after thirteen years", Coastal Engineering. Proceedings of the 30th International Conference, 4167-4178 pp.

GÓMEZ-PINA, G., FAGES, L., ROMÁN-SIERRA, J., NAVARRO, M., GIMÉNEZ-CUENCA, M., RUIZ, J.A. y MUÑOZ-PÉREZ, J.J. (2007): "An example of Integrated Coastal Management in Punta Candor (Co. Rota, Spain)", en Conferencia Internacional sobre Restauración y Gestión de las Dunas Costeras, Santander.

GÓMEZ ZOTANO, J. (2006): Naturaleza y paisaje en la Costa del Sol Occidental. Servicio de Publicaciones. Centro de Ediciones de la Diputación de Málaga (CEDMA). Málaga.

GÓMEZ ZOTANO,J. (2007): "Ecosistemas dunares de la provincia de Málaga: desconocidosy amenazados", en II Congreso andaluz de desarrollo sostenible. Una mirada a nuestras costas, Universidad de Cádiz Federación Andaluza de Ciencias Ambientales. Granada.

GÓMEZ ZOTANO, J. (2009a): "La vegetación litoral del sector oriental de la costa de Granada", en: Gómez Zotano J., Ortega Alba F. (eds.), El Sector Central de las Béticas: una visión desde la Geografía Física, Editorial Universidad de Granada. Asociación de Geógrafos Españoles (AGE). Granada, 343-355 pp.

GÓMEZ ZOTANO, J. (dir.) (2009b): Dunas litorales y fondos marinos del Saladillo-Matas Verdes (Estepona, Málaga). Estudio integrado para su declaración como reserva marítimo-terrestre. Asociación Grupo de Trabajo Valle del Genal - Servicio de Publicaciones de la Universidad de Málaga (SPICUM). Málaga.

GÓMEZ ZOTANO, J., JIMÉNEZ OLIVENCIA, Y., PORCEL RODRÍGUEZ, L. y CAMACHO CASTILLO, J. (2009): "El litoral de la Baja Alpujarra: crisis y protección de sus paisajes", en J. Gómez Zotano y F. Ortega Alba (eds.), El Sector Central de las Béticas: una visión desde la Geografía Física. Editorial Universidad de Granada - Asociación de Geógrafos Españoles (AGE). Granada, 325-342 pp.

GRACIA, FJ., DEL RÍO, L., ALONSO, C., BENAVENTE, J. y ANFUSO, G. (2006). "Historical evolution and present state of the coastal dune systems in the Atlantic coast of Cádiz (SW Spain): Palaeoclimatic and environmental implications", Journal of Coastal Research, 48, 55-63 pp.

GRACIA PRIETO, FJ., BENAVENTE GONZÁLEZ, J., ALONSO VILLALOBOS, C., DEL RÍO RODRÍGUEZ, L., ABARCA, J.M., ANFUSO MELFI, G. y GARCÍA DE LOMAS, J. (2011): "Las dunas del litoral gaditano", en: Sanjaume Saumell E.; Gracia Prieto FJ. (eds.), Las dunas en España. Sociedad Española de Geomorfología, 359-384 pp.

GREENPEACE (2010): Informe Destrucción a toda Costa, Andalucía. Greenpeace.

HERNÁNDEZ CALVENTO, L. y VALLEJO VILLALTA, I. (2008): "Características geomorfológicas y análisis de la evolución reciente del sistema de dunas activas del Parque Nacional de Doñana (1956-2001)", Boletín de la Asociación de Geógrafos Españoles, 46, 456-458 pp.

JUNTA DE ANDALUCÍA (2008): Propuesta de Estrategia Andaluza de Gestión Integrada de Zonas Costeras. Consejería de Medio Ambiente. Junta de Andalucía.

JUNTA DE ANDAluCíA (2013): Plan Director de Puertos de Andalucía 2014-2020. Agencia Pública de Puertos de Andalucía. Junta de Andalucía.

JUNTA DE ANDALUCíA (2010): Mapa de unidades fisiográficas del litoral de Andalucía. Consejería de Medio Ambiente. Junta de Andalucía.

JUNTA DE ANDALUCÍA (2010): Inventario de presas y embalses de Andalucía. Consejería de Medio Ambiente y Ordenación del Territorio. Junta de Andalucía.

LARIO, J., ZAZO, C. y GOY, J.L. (1999): "Fases de progradación y evolución morfosedimentaria de la flecha litoral de Calahonda (Granada) durante el Holoceno", Estudios Geológicos, 55, 247-250 pp.

LÓPEZ MARTOS, J.M., FRÍAS, A., NAVARRO, J., SCHWARZER, H. y VARGAS, V. (2010): Guías de Almería, Territorio, Cultura y Arte. Naturaleza almeriense: espacios del litoral. Instituto de Estudios Almerienses. Almería.

LORES CALERO, B. (2007): "Patrimonio Geológico del litoral de Almería”, Paralelo 37, 19, 45-58 pp. MÁLVAREZ, G., LARIO, J., ZAZO, C., GOY, J.L. y LUQUE, L. (1998): “Geomorfología litoral y cárstica en la Penibética malagueña”, en: Gómez, A.; Salvador Franch, F; Schulte. L.; García Navarro, A. (eds.), Itinerarios geomorfológicos por Andalucía Oriental, Publicaciones de la Universidad de Barcelona, 9-28 pp. 
MARTÍNEZ, M.L., MAUN, M. y PSUTY, N.P. (2008): "The Fragility and Conservation of the World's Coastal Dunes: Geomorphological, Ecological and Socioeconomic Perspectives", en: Martínez M.L.; Psuty N.P. (eds.), Coastal Dunes, Springer Verlag, 355-369 pp.

MCKINNEY, M.L. (2006): "Urbanization as a major cause of biotic homogenization", Biological Conservation, 127(3), 247-260 pp.

MENANTEAU, L. (1994): "Patrimoine maritime et tourisme: les potentialités du littoral atlantique de l'Andalousie", en Desarrollo regional y crisis del turismo en Andalucía: Actas del simposio hispanofrancés. Instituto de Estudios Almerienses. Almería, 109-132 pp.

MINISTERIO DE MEDIO AMBIENTE (2006): Inventario de los sistemas dunares de la provincia de Cádiz. Madrid.

MUÑOZ PÉREZ, J.J., NAVARRO, M., ROMÁN-SIERRA, J., TEJEDOR, B., RODRÍGUEZ, I. y GÓMEZPINA, G. (2009): "Long-term evolution of a transgressive migrating dune using reconstruction of the EOF method", Geomorphology, 112, 167-177 pp.

NAVARRO, M., MUÑOZ PÉREZ, J.J., ROMÁN-SIERRA, J., TEJEDOR, B., RODRÍGUEZ, I. y GÓMEZPINA, G. (2007): "Morphological evolution in the migrating dune of Valdevaqueros (SW Spain) during an eleven-year period", Internacional Conference on Management and Restoration of Coastal Dunes.

OJEDA, J., BORGNiet, L., PÉREZ, A., PÉREZ, A. y LODER, J. (2002): "Monitoring morphological changes along the coast of Huelva (SW Spain using soft-copy photogrammetry and GIS)", Journal of Coastal Conservation, 8, 69-76 pp.

OJEDA, J., VALLEJO, I. y MALVAREZ, G.C. (2005): "Morphometric evolution of the active dunes system of the Doñana National Park, Southern Spain (1977-1999)", Journal of Coastal Research, 49, 40-45 pp.

OJEDA ZÚJAR, J., DÍAZ CUEVAS, M.P., PRIETO CAMPOS, A. y ÁlVAREZ FRANCOSO, J.I. (2013): "Línea de costa y Sistemas de Información Geográfica: modelo de datos para la caracterización y cálculo de indicadores en la costa andaluza", Investigaciones Geográficas, 60, 37-52 pp.

ORTEGA SÁNCHEZ, M., LOSADA, M.A. y BAQUERIZO, A. (2003): "On the development of large-scale cuspate features on a semi-reflective Beach: Carchuna Beach, Southern Spain”, Mar. Geol., 198 (3-4), 209-223 pp.

PARACUELLOS RODRÍGUEZ, M. (2006): "Las albuferas de Adra (Almería, Sudeste Ibérico) y su relación histórica con el hombre", Revista Farua, 1, 335-358 pp.

RODRÍGUEZ RAMÍREZ, A. (2011): "Las dunas del litoral onubense", en: Sanjaume Saumell E.; Gracia Prieto F.J. (eds.), Las dunas en España. Sociedad Española de Geomorfología, 387-405 pp.

RODRÍGUEZ VIDAL, J., CÁCERES, L., RODRÍGUEZ RAMÍREZ, A. y CLEMENTE, L. (1993): "Coastal dunes and postflandrian shoreline changes. Gulf of Cadiz (SW Spain)", Mediterranean and Black sea Shorelines (INQUA) Newsletter, 15, 12-15 pp.

ROMÁN SIERRA, J., NAVARRO PONS, M., MUÑOZ-PÉREZ, J.J., GÓMEZ PINA, G. y FAGES ANTIÑOLO, L. (2004): "Ecosistemas dunares en la provincia de Cádiz: Estabilizaciones en Bolonia y Valdevaqueros, T.M. Tarifa", Revista de Obras Públicas, 151 (3450), 65-76 pp.

RUST, I. y ILLENBERG, W.K. (1996): “Coastal dunes: sensitive or not?”, Landscape and Urban Planning, 34, 165-169 pp.

SANJAUME, E. y PARDO-PASCUAL, J.E. (2011): "Degradación de sistemas dunares", en: Sanjaume Saumell E.; Gracia Prieto FJ. (eds.), Las dunas en España. Sociedad Española de Geomorfología, 609-639 pp.

TORRES ALFOSEA, FJ. (2009): "La ocupación del Dominio Público Marítimo-Terrestre en España”, Investigaciones Geográficas, 50, 63-91 pp.

VALLEJO VILLALTA, I. y OJEDA ZÚJAR, J. (2007): “Análisis morfométricos de las dunas móviles de Andalucía y Canarias: fotogrametría y Lidar- Nuevas herramientas para la difusión de la información sobre las zonas costeras", en Actas de las Jornadas Técnicas "Las nuevas técnicas de información geográfica al servicio de la gestión de zonas costeras: Análisis de la evolución de playas y dunas", 69-74 pp.

VALLEJO VILLALTA, I. y OJEDA ZÚJAR, J. (2011): "El sistema de dunas activas del Parque Nacional de Doñana", en: Sanjaume Saumell E.; Gracia Prieto FJ. (eds.), Las dunas en España. Sociedad Española de Geomorfología, 427-444 pp.

VAN DER MEULEN, F. y SALMAN, A. (1996): "Management of Mediterranean coastal dunes", Ocean $\varepsilon$ Coastal Management, 30 (2-3), 177-195 pp. 
VANNEY, J.R. y MÉNANTEAU, L. (1979): "Types de reliefs littoraux et dunaires en Basse-Andalousie (de la ría de Huelva à l'embochure du Guadalquivir)". Mélanges de la Casa de Velázquez, 15(1), 5-52 pp.

VANNEY, J.R. y MÉNANTEAU L. (2004): Géographie du Golfe ibéro-marocain. Instituto Hidrográfico. Casa de Velázquez. Lisboa.

VICIANA MARTÍNEZ-LAGE, A. (2001): Erosión Costera en Almería 1957-1995. Instituto de Estudios Almerienses. Diputación de Almería. Almería.

VICIANA MARTÍNEZ-LAGE, A., SEGURA RECHE, E., RODRÍGUEZ VAQUERO, J.E. (2006): Guías de Almería, Territorio, Cultura y Arte. El litoral mediterráneo. Instituto de Estudios Almerienses. Almería.

ZAZO, C., MERCIER, N., SILVA, P., DABRIO, C.J., GOY, J.L., ROQUERO, E., SOLER, V., BORJA, F., LARIO, J., POLO, D. \& LUQUE, L. (2005): "Landscape evolution and geodynamic controls in the Gulf of Cadiz (Huelva coast, SW Spain) during the Late Quaternary", Geomorphology, 68, 269-290 pp.

ZAZO CARDEÑA, C., DABRIO GONZÁLEZ, C.J., GOY GOY, J.L., BORJA BARRERA, F., SILVA BARROSO, P.G., LARIO, J., ROQUERO, E., BARDAJI, T., CABERO, A., POLO, D. y BORJA BARRERA, C. (2011): "El complejo eólico de El Abalario (Huelva)", en: Sanjaume Saumell E.; Gracia Prieto FJ. (eds.), Las dunas en España. Sociedad Española de Geomorfología, 407-425 pp. 